\title{
Testicular Adrenal Rests Tumors and Testicular Microlithiasis in a Brazilian Case Series with Classic Congenital Adrenal Hyperplasia
}

\author{
Laura Ohana Marques Coelho de Carvalho, ${ }^{1}$ Raymundo Miguel Garcia Lora, ${ }^{1}$ Claudia Renata Rezende \\ Penna, ${ }^{2}$ and Izabel Calland Ricarte Beserra ${ }^{3, *}$ \\ ${ }^{1}$ Postgraduate Student of Federal University of Rio de Janeiro, Brazil \\ ${ }^{2}$ Head of Radiology Unit, Instituto de Puericultura e Pediatria Martagao Gesteira, Federal University of Rio de Janeiro, Brazil \\ ${ }^{3}$ Head of Endocrinology Unit, Instituto de Puericultura e Pediatria Martagao Gesteira, Federal University of Rio de Janeiro and Professor of Pediatric Endocrinology, Federal \\ University of Rio de Janeiro, Brazil \\ "Corresponding author: Izabel Calland Ricarte Beserra, Praca Tele Santana 45 ap, 302, bloco 2, Barra da Tijuca, CEP: 22793.298, Rio de Janeiro, Brazil. Tel: +55-213938-4811, Fax: \\ +55-212590-4891, E-mail: izabelcalland@gmail.com
}

Received 2016 July 26; Revised 2016 November 28; Accepted 2016 December 10.

\begin{abstract}
Background: Testicular adrenal rest tumors are a benign condition characterized by the presence of remnants of adrenal tissue within the testes that can lead to infertility. Testicular microlithiasis are calculus deposits within the seminiferous tubules. Both are described in congenital adrenal hyperplasia.

Objectives: Describe the frequency of testicular adrenal rest tumors and testicular microlithiasis in a Brazilian case series of patients with classic congenital adrenal hyperplasia and to also relate these changes to disease control and hypothalamic-pituitarygonadal axis disorders.

Methods: Case series study. An ultrasound examination of the scrotum was performed on 12 patients between the ages of 5.33 to $22(14.72 \pm 5.26)$ years. Testicular adrenal rest tumors were classified according to the degree of testicular infiltration in stages by adapting the Grinten's classification, ranging from the absence of testicular adrenal rests visible by ultrasound (stage $\leq 1)$ to chronic obstruction of the testicular parenchyma with irreversible damage of the testicle (stage 5).

Results: Six patients ( 5 salt wasting and 1 simple virilizing) with an average age of $17.27 \pm 3.09$ years and have gone through puberty showed testicular adrenal rest tumors (Grinten stage $\geq 3$ ). In 2 of the patients there was a coincidence with testicular microlithiasis. The frequency of testicular adrenal rest tumors did not relate with the levels of serum 17-hydroxyprogesterone and androstenedione. In 3 patients with testicular adrenal rest tumors, gonadotropin levels were suggestive of hypergonadotropic hypogonadism and one of hypogonadotropic hypogonadism.

Conclusions: Testicular adrenal rest tumors were found in greater frequency during puberty and was not related to hormonal control in this group. Some of them happened with testicular microlithiasis.
\end{abstract}

Keywords: Adrenal Rest Tumor, Testicular Microlithiasis, Congenital Adrenal Hyperplasia

\section{Introduction}

Congenital adrenal hyperplasia $(\mathrm{CAH})$ is a genetic disorder of adrenal steroidogenesis resulting from mutations in one of the enzymes required for synthesis of glucocorticoids and mineralocorticoids. In $90 \%$ of the cases, 21-hydroxylase enzyme is responsible for the CAH $(1,2)$. The impaired glucocorticoid feedback inhibition at adenohypophysis level leads to compensatory increase of adrenocorticotropic-releasing hormone (ACTH) as well as production of androgens and steroid precursors prior to the enzymatic defect $(1,2)$. Male infertility in adulthood is the main concern in this population, which is due to gonadal failure caused by testicular adrenal rests tumors (TART) $(1,3)$. These tumors result from the failure in the migration of cells of the adrenal cortex, which have the same origin of primordial gonads. These cells migrate together and nestle within the gonadal tissue $(1,3-5)$.

TART could be found in normal newborns as well as infants (4). In some patients with CAH, Addison's disease, and Nelson syndrome occur as an abnormal growth of TART due to high levels of ACTH, which stimulate adrenal rest (3, 6).

TART prevalence in patients with CAH ranges from 0 to $94 \%$, depending on the selected population and tumor detection mode (1). Some factors such as the patients' age, CAH type, and hormonal control of the disease can influence the prevalence of the theses tumors (7-11). Magnetic resonance and scrotal ultrasound (US) are good methods for the detection and monitoring of TART (1).

The presence of TART in a patient with CAH could lead to infertility due to direct compression of seminiferous tubules and/or paracrine toxicity from sexual steroids 
produced by TART $(1,2,5,6)$. Serum hormonal levels of luteinizing hormone ( $\mathrm{LH})$, follicle-stimulant hormone (FSH), testosterone ( $\mathrm{T}$ ), and inhibin B could be impaired, therefore it is important to measure these hormonal levels to assess gonadal function of all patients with TART (7, 9).

The extension of TART in the gonadal tissue is correlated to the degree of testicular failure. Grinten at al. suggest a classification, which is based on clinical, histological, and radiologic findings $(1,2)$. This classification ranges from undetectable (radiologic finding) to final stage of evolution, which chronic parenchyma compression and obstruction lead to irreversible damage of testicular tissue, each one with different levels of infertility $(1,2)$.

Patients with $\mathrm{CAH}$ also have an increased frequency of testicular microlithiasis (TM) (12). It is inferred that such a condition is a result of cellular degeneration due to several causes; one of these being TART (12).

The aim was to describe the prevalence of TART and TM in males with $\mathrm{CAH}$ as well as with different ages, and to also relate the presence of these conditions with hormonal control of the disease, besides alteration of hypothalamicpituitary-gonadal axis associated to them, and insert them into the different degrees of development of TART according to the classification proposed by Grinten et al. $(1,2)$.

\section{Methods}

From January 2011 to August 2011, we evaluated 12 male patients with clinical and laboratory diagnosis of classic $\mathrm{CAH}$ [ 6 salt-wasting (SW) and 6 simple virilizing (SV)]. Scrotal US examination was performed in all patients. The average age was $14.72 \pm 5.26$ (5.33 - 22) years and all being pubertal at the time of evaluation.

Patients were divided according to the stage of growth in: growing group (group 1: patients 1, 2 and 3) and final height group (group 2: patients 4 -12). It was the criteria for definition of final height, growth rate $\leq 2 \mathrm{~cm} /$ year, and/or bone age $\geq 16$ years. Regarding group 1,1 patient was SW and 2 were SV, with a mean age \pm standard deviation (SD) of $7.19 \pm 1.46$ years ( $5.33,7.33$ and 8.91, respectively). In group 2,5 patients were SW and 4 were SV, with a mean age \pm SD of $17.23 \pm 3.33$ years (12.16 - 22).

The study was approved by the ethics committee institutional. Consent was obtained from parents of patients (or from patients, when in civil majority) prior to enrollment in the study.

Physical examination, anthropometric measurements, and hormone assays were performed on all patients. Target height $(\mathrm{TH})$ was calculated using the formula: father's height $(\mathrm{cm})+$ mother's height $(\mathrm{cm})$ divided for $2+6.5$. Height standard deviation scores (SDS) and
TH SDS were calculated according to age and sex-specific NCHS standards. Pubertal development was evaluated and classified (Tanner staging) (13). Bone age was evaluated by the Greulich and Pyle method (14).

It was defined as good control of $\mathrm{CAH}$ when serum level of 17-hydroxyprogesterone (17OHP) $\leq 10 \mathrm{ng} / \mathrm{mL}$ and poor control when above this value $(15,16)$. The control was considered suppressed when androstenedione $(\Delta 4)$ levels are below normal for their age (9) (children: $<0.3 \mathrm{ng} / \mathrm{mL}$ and men $<0.4 \mathrm{ng} / \mathrm{mL}$ ). 17OHP and plasma renin were determined by radioimmunoassay and $\Delta 4$ by chemiluminescence. Serum levels of LH and FSH were also evaluated by chemiluminescence.

At the time of evaluation, all 3 patients in group 1 were using prednisolone. In group 2, 4 patients were using dexamethasone, 3 were using prednisone, and the remaining 2 were using prednisolone. For purposes of comparative analysis of glucocorticoid, doses used were converted to equivalent dose of hydrocortisone in proportion: hydrocortisone $20 \mathrm{mg}=0.75 \mathrm{mg}$ of dexamethasone and $5 \mathrm{mg}$ of prednisone or prednisolone $(11,17)$. The mean hydrocortisone dose was $10.56 \pm 2.74 \mathrm{mg} / \mathrm{m}^{2} /$ day in group 1 and $11.88 \pm 4.16 \mathrm{mg} / \mathrm{m}^{2} /$ day in group 2 . The $6 \mathrm{SW}$ were also using fludrocortisone $(0.1 \mathrm{mg} /$ day). All patients in group 1 evolved with central precocious puberty and were being treated with leuprolide acetate depot. Of the group 2, 6 patients had made previous use of leuprolide acetate depot (patients 4, 5, 6, 7, 8 and 9).

Scrotal US was performed by single experienced radiologist, in all cases, using a Nemio 30 Toshiba. Tests were assessed in 3 dimensions, being measures defined by longitudinal (L), anteroposterior (AP), and transverse (Tr). Testicular volume is defined by the formula: AP x L x Tr x 0.52. Normal values for the age group 1 - 18 years have been based on the Goede et al. curve (18). Patients older than 18 years were classified in reduced when $<6 \mathrm{~mL}$, normal when 6 to 31.8 $\mathrm{mL}$ and increased when $>31.8 \mathrm{~mL}$ (19). TARTs were assessed in 3 dimensions: maximum diameter (dmax), mean diameter (dmea), and minimum diameter (dmin) and the TART volume calculated by the formula: dmax $\mathrm{x}$ dmea $\mathrm{x}$ dmin $\mathrm{x}$ 0.52. TARTs were classified based on Grinten's stages $(1,2)$.

\section{Results}

Scrotal US showed presence of bilateral TART in 6/12 patients $(7-12)$. TM appeared in 2 patients ( 8 and 11) in both testicles. In all cases, TART and TM were found in group 2. None of the patients in group 1 had testicular alteration detectable by US.

Group 2 was divided based on the presence on TART by US: with TART $(n=3)$ and without $(n=6)$. All patients without TART were SV. In the TART group, 5 were SW and 1 was VS. 
Patients with TM presented limited amount of microlithos ( $<5 /$ testicle), one of them had used aGnRH.

All patients range from degree 3, 4, and 5, based on Grinten et al. classification (1,2).

TART was identified in 4 patients by clinical exam. All cases were confirmed by US. Maximum diameter varied from 0.8 to $2.2 \mathrm{~cm}$ and volume from 0.062 to $3.42 \mathrm{~cm}^{3}$ (Table 1). One of the patients with bilateral TART by US and by clinical evaluation only found unilateral alteration, in addition to this; the patient had scrotal calculi and bilateral hydrocele. Clinical evaluation had a sensibility of $58.3 \%$ when compared to the US evaluation. TART only detected by US, had a maximum diameter range from 0.5 to 2.0

All TART identified by palpation were stage 3 or more. Grinten et al. classified patients with undetectable TART by palpation as stage 3 or less. As demonstrated in Table 1. All patients with TM were stage 3 (Table 2).

Two patients with concomitant TART and TM presented other testicular alteration. One patient had epididymal cyst and another hydrocele. Two patients had scrotal calculi in association with TART, 1 with TM and another without. Both patients with scrotal calculi had hydrocele by US. One patient had varicocele.

There was inadequate testicular volume in the group 1 and in the subgroup with TART. All 3 patients in group 1 had an increase in the testicular volume. In group 2, 2 patients had testicular volume increased and 1 was testicular atrophy. In the subgroup without TART, all patients had adequate testicular volume (Tables 2 and 3 ).

The comparison between the groups, with respect to weight, height, body mass index (BMI), hormone levels, history of central precocious puberty, and type of CAH is shown in Table 3.

Patient 7, the only one with TART and SV-CAH, presented elevated LH and normal T. Hormonal control at initial assessment was normal. Clinical evaluation exhibited hard and irregular testicles. By US was confirmed bilateral TART stage 3.

Patient 9 with TART displayed low LH and FSH levels, a normal T, which suggest hypogonadotropic hypogonadism; caused by conversion of androgens to estrogen, and resulting in gonadotropin suppression. This patient had the greatest testicular volume.

Patient 10, with grades 4 and 5 of TART, presented laboratory data suggestive of dysfunction of Sertoli cells, which was evidenced by the rise in FSH levels. The measurement of inhibin-B was $10.4 \mathrm{pg} / \mathrm{mL}$ (ref. < 400). However, semen analysis was not performed on the patient. Laboratory evaluation revealed adrenal levels of $17 \mathrm{OHP}$ and $\Delta 4$ that characterized hormonal suppression. However, the patient did not make proper use of medication until the time of the first clinical evaluation of this research, when it began to carry out the treatment properly, a fact that may have led to suppression of markers of CAH control.

Patient 12, the only patient with TART grade 5 of Grinten bilateral, showed significant hormonal changes, with elevated FSH and LH, however with normal T, despite the adequacy of activity markers of $\mathrm{CAH}$ at the time of evaluation. Furthermore, conducted dose of inhibin-B and the result was $29.6 \mathrm{pg} / \mathrm{mL}$ (ref. < 400). Semen analysis was not performed in the patient. Clinically, the patient had hardened testicles and irregularity on palpation, and poor clinical control as evidenced by hyperpigmentation of skin and mucous membranes. Inadequate control of chronic CAH was also suggested by a short adult height (SDS: 4.73), below the TH (SDS: -2.6). The US revealed reduced testicular volume and a diffuse infiltration of the TART, being the patient with lower testicular volume amongst patients in group 2. Together, these data suggests a hypergonadotropic hypogonadism likely by direct injury to testicular parenchyma by the TART.

\section{Discussion}

Despite the small population, this study depicted a high frequency of TART in patients with CAH. It was more representative in a group in the final height (group 2). Other authors $(3,9,11,12,15,20,21)$ had related a positive correlation between age, pubertal stage, and presence of TART, with the highest prevalence in adults (22), up to $94 \%$ $(7,8)$. All these findings reinforce hypothesis of LH elevation as an important factor in development of TART $(9,10)$, which are present since the intrauterine period, but are more prevalent in adulthood (2).

TART presence was more frequent in SW-CAH. Nevertheless, all authors have not found this finding. Some studies report similar results to ours $(9,23)$. This fact may be justified by presence of ACTH and angiotensin II receptors in TART, which are greater in patients with SW-CAH (6). However for methodological reasons it was not possible to evaluate the ACTH levels in our sample.

Palpation shows a low sensibility $(3,7-9,23)$. In our study, it only detected 7 over the 12 testicles with TART. By US, we also found a presence of scrotal calculi in one of the assessed gonads; which could be a misleading factor during the clinical exam. Scrotal calculi's etiology is not well defined, however it could be a consequence of hematomas, inflammatory process, torsions, and infarcts of testicles and epididymis. It has been reported in association with epididymis's cyst, epididymitis, varicocele, hydrocele, and testicular microlithiasis (24). As an interesting finding, 1 of the patients with bilateral scrotal calculi had TM as well. Both patients had hydrocele and TART. We did not find any medical study reporting an association between TART and 
Table 1. Age, CAH Type, TART Detection by Clinical Evaluation, Stage of TART by Grinten et al. (1,2) TART Dimensions and Testicular Volume All Patients

\begin{tabular}{|c|c|c|c|c|c|c|}
\hline Patient & Age, $y$ & CAH Type & TART Palpated, $\mathbf{R} / \mathbf{L}$ & Stage $^{\mathrm{a}}, \mathbf{R} / \mathrm{L}$ & TART Dimension R/L, cm & Testicular Vol. R/L, mL \\
\hline $\mathbf{1}$ & 5.33 & SW & $\mathrm{N} / \mathrm{N}$ & $\leq 1 / \leq 1$ & & $1.8 / 1.5(\uparrow)$ \\
\hline 2 & 7.33 & SV & $\mathrm{N} / \mathrm{N}$ & $\leq 1 / \leq 1$ & & $2.53 / 2.92(\uparrow)$ \\
\hline 3 & 8.91 & SV & $\mathrm{N} / \mathrm{N}$ & $\leq 1 / \leq 1$ & & $2.70 / 2.32(\uparrow)$ \\
\hline 4 & 12.83 & SV & $\mathrm{N} / \mathrm{N}$ & $\leq 1 / \leq 1$ & - & $5.69 / 5.15(\mathrm{~N})$ \\
\hline 5 & 16.58 & SV & $\mathrm{N} / \mathrm{N}$ & $\leq 1 / \leq 1$ & - & $10.22 / 10.1(\mathrm{~N})$ \\
\hline 6 & 22.0 & SV & $\mathrm{N} / \mathrm{N}$ & $\leq 1 / \leq 1$ & - & $11.13 / 10.4(\mathrm{~N})$ \\
\hline 7 & 17.75 & SV & $\mathrm{Y} / \mathrm{N}$ & $3 / 3$ & $2.0 \times 1 \times 0.8$ e $0.4 \times 0.3 \times 0.3^{b} / 2.0 \times 0.7 \times 0.6$ & $12.52 / 10.94(\mathrm{~N})$ \\
\hline 8 & 12.16 & SW & $\mathrm{N} / \mathrm{N}$ & $3 / 3$ & $0.7 \times 0.4 \times 0.3 / 0.7 \times 0.4 \times 0.3$ & $10.14 / 9.25(\uparrow)$ \\
\hline 9 & 14.33 & SW & $\mathrm{Y} / \mathrm{Y}$ & $5 / 4$ & $1.8 \times 1.5 \times 1.3 / 2.2 \times 2.0 \times 1.5$ & $23.08 / 18.17(\uparrow)$ \\
\hline 10 & 18.42 & SW & $\mathrm{Y} / \mathrm{Y}$ & $5 / 4$ & $0.8 \times 0.5 \times 0.3 / 1.0 \times 0.8 \times 0.8$ & $11.18 / 11.93(\mathrm{~N})$ \\
\hline 11 & 20.25 & SW & $\mathrm{N} / \mathrm{N}$ & $3 / 3$ & $0.5 \times 0.5 \times 0.3 / 0.7 \times 0.5 \times 0.4$ & $12.89 / 11.36(\mathrm{~N})$ \\
\hline 12 & 20.75 & SW & $\mathrm{Y} / \mathrm{Y}$ & $5 / 5$ & $2.7 \times 2.0 \times 1.6 / 1.8 \times 1.2 \times 1.0$ & $4.5 / 4.5(\downarrow)$ \\
\hline
\end{tabular}

Abbreviations: L, left; N, no; R, right; SV, simple virilizing; SW, salt wasting; Y, yes.

${ }^{a}$ Classification modified of Grinten 1,2: $\leq 1$ ( $\leq$ Stage 1): Absence or presence of adrenal rest cells within the rete testis, not detectable by scrotal US; 2 (Stage 2): The adrenal rest cells may become visible by US as one or more small hypoechogenic lesions; 3 (Stage 3): Further growth of the adrenal rest cells will compress the rete testis. In pubertal or postpubertal CAH patients, oligo or azoospermia may already be found due to obstruction of the seminiferous tubules. Signs of gonadal dysfunction such as decreased inhibin B and increased FSH and LH levels may also be present; 4 (Stage 4); Further hypertrophy and hyperplasia of the adrenal rest cells with progressive obstruction of the rete testis may lead to induction of fibrosis within the tumor and focal lymphocytic infiltration. Several small tumors within the rete testis will conflate, forming a single lobulated structure separated from the residual testicular tissue by fibrous strands. Peritubular fibrosis can be found in the surrounding testicular tissue, indicating early testicular damage; 5 (Stage 5): Chronic obstruction subsequently will lead to destruction of the surrounding testicular parenchyma with irreversible damage of the testis.

${ }^{\mathrm{b}}$ Patient 2 had two TART on the right testis.

Table 2. Occurence of TART and TM with US Average Testicular Volume, Hormonal Control, and Hormonal Levels of Hypothalamic-Pituitary-Gonadal Axis in All Patients

\begin{tabular}{|c|c|c|c|c|c|c|c|c|}
\hline Patient & Age, $y$ & $\begin{array}{l}\text { Stage TART by } \\
\text { Grinten, } R / L\end{array}$ & Microlithiasis, R/L & $\begin{array}{c}\text { US Average } \\
\text { Testicular Vol, mL }\end{array}$ & Hormonal Control & FSH, mUI/mL & LH mUI/mL & $\mathrm{T}, \mathbf{n g} / \mathbf{m L}$ \\
\hline 1 & 5.33 & $(\leq 1 / \leq 1)$ & $(-/)$ & $1.65(\uparrow)$ & No & $0.9(\mathrm{~N})$ & $1.4(\mathrm{~N})$ & $522(\uparrow)$ \\
\hline 2 & 7.33 & $(\leq 1 / \leq 1)$ & $(-/)$ & $2.73(\uparrow)$ & No & $0.2(\mathrm{~N})$ & $0.1(\mathrm{~N})$ & $25(\mathrm{~N})$ \\
\hline 3 & 8.91 & $(\leq 1 / \leq 1)$ & $(-/)$ & $2.51(\uparrow)$ & No & $0.6(\mathrm{~N})$ & $0.7(\mathrm{~N})$ & $62(\mathrm{~N})$ \\
\hline 4 & 12.83 & $(\leq 1 / \leq 1)$ & $(-/)$ & $5.42(\mathrm{~N})$ & No & $8.2(\mathrm{~N})$ & $3.6(\mathrm{~N})$ & $359(\uparrow)$ \\
\hline 5 & 16.58 & $(\leq 1 / \leq 1)$ & $(-1-)$ & $10.16(\mathrm{~N})$ & No & $3.6(\mathrm{~N})$ & $3(\mathrm{~N})$ & $485(\mathrm{~N})$ \\
\hline 6 & 22 & $(\leq 1 / \leq 1)$ & $(-/)$ & $10.77(\mathrm{~N})$ & Suppressed & $8.6(\mathrm{~N})$ & $10.3(\uparrow)$ & $259(\downarrow)$ \\
\hline 7 & 17.75 & $(3 / 3)$ & $(-/)$ & $11.73(\mathrm{~N})$ & Yes & $5.1(\mathrm{~N})$ & $10.4(\uparrow)$ & $326(\mathrm{~N})$ \\
\hline 8 & 12.16 & $(3 / 3)$ & $(+/+)$ & $9.70(\uparrow)$ & Suppressed & $3.5(\mathrm{~N})$ & $2(\mathrm{~N})$ & $309(\uparrow)$ \\
\hline 9 & 14.33 & $(5 / 4)$ & $(-/)$ & $20.63(\uparrow)$ & No & $0.6(\downarrow)$ & $0.07(\downarrow)$ & $592(\mathrm{~N})$ \\
\hline 10 & 18.42 & $(5 / 4)$ & $(-H)$ & $11.56(\mathrm{~N})$ & Suppressed & $15.3(\uparrow)$ & $5.8(\mathrm{~N})$ & $328(\mathrm{~N})$ \\
\hline 11 & 20.25 & $(3 / 3)$ & $(+++)$ & $12.13(\mathrm{~N})$ & Yes & $4,4(\mathrm{~N})$ & $4.5(\mathrm{~N})$ & $505(\mathrm{~N})$ \\
\hline 12 & 20.75 & $(5 / 5)$ & $(-H)$ & $4,5(\downarrow)$ & Yes & $30.4(\uparrow)$ & $18.5(\uparrow)$ & $419(\mathrm{~N})$ \\
\hline
\end{tabular}

Abbreviation: N, normal.

scrotal calculi. Therefore is questionable if this association is a consequence of base disease, or a simple coincidence. More studies are necessary to confirm it.

All of TART detected by palpation was classified as de- gree 4 or 5 in Grinten's scale. With the exception of the patient described earlier, such patients had TART level 3 and scrotal calculi of $0.4 \mathrm{~cm}$. Hence it is difficult to affirm that TART degree 3 or less can be found by palpation. Fur- 
Table 3. Comparison Between Group 1 and Subgroups With and Without TART Group 2 Regarding Age, Height, Weight, BMI, TH, Testicular Volume, Hormonal Values, Type of HAC and History of Central Precocious Puberty (CPP)

\begin{tabular}{|c|c|c|c|}
\hline & \multirow[t]{2}{*}{ Group $1^{b}(n=3)$} & \multicolumn{2}{|c|}{ Group $2^{c}$} \\
\hline & & Without TART $(n=3)$ & With TART $(n=6)$ \\
\hline Age, $y$ & $7.19 \pm 1.46$ & $17.13 \pm 3.76$ & $17.27 \pm 3.09$ \\
\hline Height, cm & $141.56 \pm 5.09$ & $159.06 \pm 3.57$ & $156.21 \pm 7.94$ \\
\hline SDS Height & $3.56 \pm 1.48$ & $-1.3 \pm 1.57$ & $-1.94 \pm 1.61$ \\
\hline Weight, kg & $38.36 \pm 5.96$ & $62.33 \pm 9.81$ & $60.7 \pm 7.14$ \\
\hline SDS Weight & $2.65 \pm 2.11$ & $0.17 \pm 1.23$ & $-0.18 \pm 1.23$ \\
\hline BMI, $\mathrm{kg} / \mathrm{m}^{2}$ & $19.08 \pm 2.20$ & $24.50 \pm 2.73$ & $24.82 \pm 1.68$ \\
\hline SDS BMI & $1.48 \pm 2.18$ & $0.99 \pm 0.57$ & $0.97 \pm 0.56$ \\
\hline TH, cm & $175.6 \pm 4.71$ & $169.51 \pm 5.28$ & $170.34 \pm 7.85$ \\
\hline Testic SDS TH & $-0.17 \pm 0.81$ & $-1.02 \pm 0,9$ & $-0.9 \pm 1.2$ \\
\hline Testicular Volume, mL & $2.29 \pm 0.46$ & $8.78 \pm 2.38$ & $11.70 \pm 4.75$ \\
\hline 17OHP, ng/mL & $20.10 \pm 3.64$ & $48.28 \pm 32.57$ & $21.02 \pm 37.61$ \\
\hline$\Delta 4, \mathrm{ng} / \mathrm{mL}$ & $6.23 \pm 3.02$ & $3.50 \pm 2.74$ & $2.31 \pm 3.46$ \\
\hline Plasma Renin, ng/mL & $3.23 \pm 2.21$ & $2.80 \pm 0.40$ & $2.31 \pm 1.55$ \\
\hline FSH, $\mathbf{m U I} / \mathbf{m L}$ & $0.56 \pm 0.28$ & $6.80 \pm 2.26$ & $9.88 \pm 10.24$ \\
\hline $\mathrm{LH}, \mathrm{mUI} / \mathrm{mL}$ & $0.73 \pm 0.53$ & $5.63 \pm 3.30$ & $6.87 \pm 6.11$ \\
\hline T ng/mL & $20.3 \pm 226.07$ & $367.66 \pm 92.46$ & $413.16 \pm 105$ \\
\hline SV-CAH, n & 2 & 3 & 1 \\
\hline SW-CAH, n & 1 & 0 & 5 \\
\hline $\mathrm{CPP}, \mathrm{n}$ & 3 & 2 & 5 \\
\hline
\end{tabular}

Abbreviation: $\mathrm{TH}$, target height; $\Delta 4$, androstenedione.

${ }^{\mathrm{a}}$ Values are expressed as mean \pm standard deviation (SDS).

${ }^{\mathrm{b}}$ Patients were divided according to the stage of growth in group 1: growing group (patients 1, 2 and 3 ).

'Group 2: final height group (patients 4 -12).

thermore, some authors suggest that only TART over $2 \mathrm{~cm}$ can be found by palpation $(1,7,25)$. Meanwhile, our study detected TART with a maximum diameter less than $2 \mathrm{~cm}$, which is in contradiction with related previously. Therefore, we suppose that not only the diameter of the tumor allow its clinical detection, but also the testicular infiltration, represented by Grinten classification. The more infiltrated the tumor is, it confers more consistency and irregularity to the testicle, which ease its detection through palpation. This is a relevant hypothesis, which has not been presented by previous studies; there will need to more studies done for this to be confirmed.

TM is more prevalent in patients with $\mathrm{CAH}$, especially when TART is present, and in more advanced ages (12). It is supposed that the presence of TART can induce development of TM, which would cause atrophy and degeneration of seminiferous tubules (12). Association between TM and fertility changes has been reported (26), however comparable to our findings, Pourazoglu et al., did not find changes in gonadotropins and testosterone levels that suggest gonadal failure in most patients with TM (12).

It is assumed that poor hormonal control is an important factor in the pathogenesis of TART $(1,11,21,27)$. However, TART is also found in patients that were adequately treated. This suggests that inadequate hormonal control is probably not the only cause of its high frequency $(2,7,11,15$, 21). The same as some male patients with poorly controlled CAH will never develop TART $(1,21)$. One explanation for this observation is that during the embryonic period, aberrant adrenal cells do not nestle in all men testes, but only a portion of them $(1,21)$. The presence of these aberrant cells is a requisite for the growth of TART, justifying the lack of relationship between the presence of TART and poor hormonal control1, as occurred in our study.

Changes in the hypothalamic-pituitary-gonadal axis are frequently described in patients with CAH. Some patients in our study had symptoms suggestive of hypergonadotropic hypogonadism, probably due to direct testic- 
ular injury secondary to mechanical compression of the tumor, or cellular toxicity triggered by local production of steroids $(3,7)$. The elevation of gonadotropins with normal testosterone levels may be due to excessive production of androgens in $\mathrm{CAH}$, in spite of the low production by the gonads (28). TART can result in obstructive azoospermia and is the leading cause of infertility in $\operatorname{CAH}(7,28,29)$.

Another cause of impaired fertility in $\mathrm{CAH}$ patients is hypogonadotropic hypogonadism, which results from suppression of gonadotropins due to estrogen production, as a consequence of peripheral conversion of androgens (30). The patient with the biggest TART volume had a decrease in gonadotropin levels with elevated androgens. We question, then, if the TART is the agent, adding to the adrenal hormone production, which enhance the production of adrenal androgens leading to uncontrolled laboratory $\mathrm{CAH}$ (28)and consequently suppression of gonadotropins, or if the uncontrolled $\mathrm{CAH}$ lead to the development of TART $(1,11)$ and also to hypogonadotropic hypogonadism $(28,30)$.

In conclusion, our results show that TART is frequent in patients with CAH. Adrenal rests seem to occur more frequently in patients SW as well as end-stage puberty individuals. Changes in testicular volume and the hypothalamicpituitary-gonad are frequent in patients with CAH. It is recommended to yearly perform scrotal US in all men with $\mathrm{CAH}$ in order to prevent late complications such as infertility. Further studies on larger patient groups are necessary in order to determine the frequency of TM as well as its association with TART and gonadal functions in these patients.

\section{References}

1. Claahsen-van der Grinten HL, Otten BJ, Stikkelbroeck MM, Sweep FC, Hermus AR. Testicular adrenal rest tumours in congenital adrenal hyperplasia. Best Pract Res Clin Endocrinol Metab. 2009;23(2):209-20. doi: 10.1016/j.beem.2008.09.007. [PubMed: 19500764].

2. Claahsen-van der Grinten HL, Hermus AR, Otten BJ. Testicular adrenal rest tumours in congenital adrenal hyperplasia. Int J Pediatr Endocrinol. 2009;2009:624823. doi: 10.1155/2009/624823. [PubMed: 19956703].

3. Martinez-Aguayo A, Rocha A, Rojas N, Garcia C, Parra R, Lagos M, et al. Testicular adrenal rest tumors and Leydig and Sertoli cell function in boys with classical congenital adrenal hyperplasia. $J$ Clin Endocrinol Metab. 2007;92(12):4583-9. doi: 10.1210/jc.2007-0383. [PubMed: 17895312].

4. Sullivan JG, Gohel M, Kinder RB. Ectopic adrenocortical tissue found at groin exploration in children: incidence in relation to diagnosis, age and sex. BJU Int. 2005;95(3):407-10. doi: 10.1111/j.1464410X.2005.05310.x. [PubMed: 15679804]

5. Fernandes VO, Barros AI, Quidute AR, Montenegro AP, Fontenele EG, Sales AP, et al. [Bilateral testicular tumors caused by congenital adrenal rest hyperplasia]. Arq Bras Endocrinol Metabol. 2009;53(8):1052-8. [PubMed: 20126861].

6. Claahsen-van der Grinten HL, Otten BJ, Sweep FC, Span PN, Ross HA, Meuleman EJ, et al. Testicular tumors in patients with con- genital adrenal hyperplasia due to 21-hydroxylase deficiency show functional features of adrenocortical tissue. J Clin Endocrinol Metab. 2007;92(9):3674-80. doi:10.1210/jc.2007-0337. [PubMed: 17595257].

7. Stikkelbroeck NM, Otten BJ, Pasic A, Jager GJ, Sweep CG, Noordam $\mathrm{K}$, et al. High prevalence of testicular adrenal rest tumors, impaired spermatogenesis, and Leydig cell failure in adolescent and adult males with congenital adrenal hyperplasia. J Clin Endocrinol Metab. 2001;86(12):5721-8. doi: 10.1210/jcem.86.12.8090. [PubMed: 11739428].

8. Stikkelbroeck NM, Suliman HM, Otten BJ, Hermus AR, Blickman JG, Jager GJ. Testicular adrenal rest tumours in postpubertal males with congenital adrenal hyperplasia: sonographic and MR features. Eur Radiol. 2003;13(7):1597-603. doi:10.1007/s00330-002-1786-3. [PubMed: 12835972].

9. Claahsen-van der Grinten HL, Sweep FC, Blickman JG, Hermus AR, Otten BJ. Prevalence of testicular adrenal rest tumours in male children with congenital adrenal hyperplasia due to 21-hydroxylase deficiency. Eur J Endocrinol. 2007;157(3):339-44. doi: 10.1530/EJE-07-0201. [PubMed: 17766717].

10. Benvenga S, Smedile G, Lo Giudice F, Trimarchi F. Testicular adrenal rests: evidence for luteinizing hormone receptors and for distinct types of testicular nodules differing for their autonomization. Eur J Endocrinol. 1999;141(3):231-7. [PubMed: 10474120].

11. Mouritsen A, Jorgensen N, Main KM, Schwartz M, Juul A. Testicular adrenal rest tumours in boys, adolescents and adult men with congenital adrenal hyperplasia may be associated with the CYP21A2 mutation. Int J Androl. 2010;33(3):521-7. doi: 10.1111/j.13652605.2009.00967.x. [PubMed: 19531083].

12. Poyrazoglu S, Saka N, Agayev A, Yekeler E. Prevalence of testicular microlithiasis in males with congenital adrenal hyperplasia and its association with testicular adrenal rest tumors. Horm Res Paediatr. 2010;73(6):443-8. doi: 10.1159/000313587. [PubMed: 20407230].

13. Marshall WA, Tanner JM. Variations in the pattern of pubertal changes in boys. Arch Dis Child. 1970;45(239):13-23. [PubMed: 5440182].

14. Greulich WW, Pyle SI. Radiologic atlas of skeletal development of the hand and wrist. California: Stanford University Press Palo Alto; 1959.

15. Cakir ED, Mutlu FS, Eren E, Pasa AO, Saglam H, Tarim O. Testicular adrenal rest tumors in patients with congenital adrenal hyperplasia. J Clin Res Pediatr Endocrinol. 2012;4(2):94-100. doi: 10.4274/jcrpe.563. [PubMed: 22672867].

16. Newm MIL, Ghizzoni KLS. An update of Congenital Adrenal Hyperplasia. Lifshitz F. Pediatric Endocrinology. New York: Informa Healthcare; 2007. pp. 227-45.

17. Furst DE, Saag KG. Glucocorticoid withdrawal 2013. Available from: http://www.uptodate.com/contents/glucocorticoid-withdrawal.

18. Goede J, Hack WWM, Sijstermans K, Van der Voort-Doedens LM, Van der Ploeg T, Meij-de Vries A, et al. Normative values for testicular volume measured by ultrasonography in a normal population from infancy to adolescence. Hormone Res Paediatr. 2011;76(1):56-64.

19. Lenz S, Giwercman A, Elsborg A, Cohr KH, Jelnes JE, Carlsen E, et al Ultrasonic testicular texture and size in 444 men from the general population: correlation to semen quality. Eur Urol. 1993;24(2):231-8. [PubMed: 8104150].

20. Peggy P, Francois D, Francois T, Christine C, Veronique K, Emmanuel S, et al. Adrenal rest tissue in gonads in 70 French patients with classical congenital adrenal hyperplasia (21 hydroxylase deficiency). Endocrine Abstracts. 2007;14:632.

21. Kang MJ, Kim JH, Lee SH, Lee YA, Shin $\mathrm{CH}$, Yang SW. The prevalence of testicular adrenal rest tumors and associated factors in postpubertal patients with congenital adrenal hyperplasia caused by 21 hydroxylase deficiency. Endocr J. 2011;58(6):501-8. [PubMed: 21521928]

22. Falhammar H, Nystrom HF, Ekstrom U, Granberg S, Wedell A, Thoren M. Fertility, sexuality and testicular adrenal rest tumors in adult males with congenital adrenal hyperplasia. Eur J Endocrinol 2012;166(3):441-9. doi: 10.1530/EJE-11-0828. [PubMed: 22157069]. 
23. Nermoen I, Rorvik J, Holmedal SH, Hykkerud DL, Fougner KJ, Svartberg J, et al. High frequency of adrenal myelolipomas and testicular adrenal rest tumours in adult Norwegian patients with classical congenital adrenal hyperplasia because of 21-hydroxylase deficiency. Clin Endocrinol (Oxf). 2011;75(6):753-9. doi: 10.1111/j.1365-2265.2011.04151.x. [PubMed: 21689130].

24. Artas H, Orhan I. Scrotal calculi. J Ultrasound Med. 2007;26(12):1775-9. [PubMed: 18029930].

25. Rutgers JL, Young RH, Scully RE. The testicular "tumor" of the adrenogenital syndrome. A report of six cases and review of the literature on testicular masses in patients with adrenocortical disorders. Am J Surg Pathol. 1988;12(7):503-13. [PubMed:3291624].

26. Sasagawa I, Nakada T, Kazama T, Satomi S, Katayama T, Matuda S. Testicular microlithiasis in male infertility. Urol Int. 1988;43(6):368-9. [PubMed: 3238835].

27. Kim HK, Crotty E. Bilateral testicular adrenal rests in a boy with con- genital adrenal hyperplasia. Pediatr Radiol. 2010;40 Suppl 1:S25. doi: 10.1007/s00247-010-1851-z. [PubMed: 20927625].

28. Claahsen-van der Grinten HL, Otten BJ, Takahashi S, Meuleman EJ, Hulsbergen-van de Kaa C, Sweep FC, et al. Testicular adrenal rest tumors in adult males with congenital adrenal hyperplasia: evaluation of pituitary-gonadal function before and after successful testis-sparing surgery in eight patients. J Clin Endocrinol Metab. 2007;92(2):612-5. doi:10.1210/jc.2006-1311. [PubMed: 17090637].

29. Marchini GS, Cocuzza M, Pagani R, Torricelli FC, Hallak J, Srougi M. Testicular adrenal rest tumor in infertile man with congenital adrenal hyperplasia: case report and literature review. Sao Paulo Med J. 2011;129(5):346-51. [PubMed: 22069134].

30. Nebesio TD, Eugster EA. Growth and reproductive outcomes in congenital adrenal hyperplasia. Int $J$ Pediatr Endocrinol. 2010;2010:298937. doi: 10.1155/2010/298937. [PubMed: 20148087]. 